\title{
Predictive modelling of the distribution of Clematis sect. Fruticella s. str. under climate change reveals a range expansion during the Last Glacial Maximum
}

\author{
Mingyu Li ${ }^{\text {Equal first author, } 1}$, Jian He ${ }^{\text {Equal first author, } 1}$, Zhe Zhao ${ }^{1}$, Rudan Lyu $^{1}$, Min Yao ${ }^{1}$, Jin Cheng ${ }^{\text {Corresp., } 1}$, Lei Xie ${ }^{\text {Corresp. } 1}$ \\ 1 Beijing Forestry University, Beijing, China \\ Corresponding Authors: Jin Cheng, Lei Xie \\ Email address: chengjin@bjfu.edu.cn, xielei@bjfu.edu.cn
}

Background. The knowledge of distributional dynamics of living organisms is a prerequisite for protecting biodiversity and for the sustainable use of biotic resources. Clematis sect. Fruticella s. str. is a small group of shrubby, yellow-flowered species distributed mainly in arid and semi-arid areas of China. Plants in this section are both horticulturally and ecologically important.

Methods. Using past, present, and future environmental variables and data with Maximum Entropy (Maxent) modeling, we evaluated the importance of the environmental variables on the section's estimated distributions, thus simulating its distributional dynamics over time. The contractions and expansions of suitable habitat between the past and future scenarios and the present were then compared.

Results and Discussion. The models revealed that the areas with high and moderate suitability currently encompass about $725,110 \mathrm{~km}^{2}$. The distribution centroid location varies between points in Ningxia and Inner Mongolia during the different scenarios. Elevation, Mean UV-B of Lowest Month, Precipitation of Coldest Quarter, and Mean Temperature of Driest Quarter were major factors determining the section's distribution. Our modeling indicated that Clematis sect. Fruticella underwent a significant range contraction during the last interglacial period, and then expanded during the last glacial maximum (LGM) to amounts like those of the present. Cold, dry, and relatively stable climate, as well as steppe or desert steppe environments may have facilitated range expansion of this cold-adapted, drought-resistant plant taxon during the LGM. Predicted future scenarios show little change in the amounts of suitable habitat for Clematis sect. Fruticella. This study aids understanding of the distributional dynamics of Clematis sect. Fruticella, and the results will help the conservation and sustainable use of these important woody plants in Chinese arid and semiarid areas. 
1 Predictive modelling of the distribution of Clematis

2 sect. Fruticella s. str. under climate change reveals a

3 range expansion during the Last Glacial Maximum

4

5 Mingyu Li, Jian He, Zhe Zhao, Rudan Lyu, Min Yao, Jin Cheng, Lei Xie

6

7 Beijing Forestry University, Beijing, PR China

8

9 Corresponding Author:

10 Jin Cheng, Lei Xie

11 No. 35, Tsinghua East Road, Haidian District, Beijing, 100083, China

12 Email address: chengj@bjfu.edu.cn (J. Cheng); xielei@bjfu.edu.cn (L. Xie) 
15

16

17

18

19

20

21

22

23

24

25

26

27

28

29

30

31

32

33

34

35

36

37

38

39

40

41

42

43

44

45

\section{Abstract}

Background. The knowledge of distributional dynamics of living organisms is a prerequisite for protecting biodiversity and for the sustainable use of biotic resources. Clematis sect. Fruticella s. str. is a small group of shrubby, yellow-flowered species distributed mainly in arid and semi-arid areas of China. Plants in this section are both horticulturally and ecologically important.

Methods. Using past, present, and future environmental variables and data with Maximum Entropy (Maxent) modeling, we evaluated the importance of the environmental variables on the section's estimated distributions, thus simulating its distributional dynamics over time. The contractions and expansions of suitable habitat between the past and future scenarios and the present were then compared.

Results and Discussion. The models revealed that the areas with high and moderate suitability currently encompass about $725,110 \mathrm{~km}^{2}$. The distribution centroid location varies between points in Ningxia and Inner Mongolia during the different scenarios. Elevation, Mean UV-B of Lowest Month, Precipitation of Coldest Quarter, and Mean Temperature of Driest Quarter were major factors determining the section's distribution. Our modeling indicated that Clematis sect. Fruticella underwent a significant range contraction during the last interglacial period, and then expanded during the last glacial maximum (LGM) to amounts like those of the present. Cold, dry, and relatively stable climate, as well as steppe or desert steppe environments may have facilitated range expansion of this cold-adapted, drought-resistant plant taxon during the LGM.

Predicted future scenarios show little change in the amounts of suitable habitat for Clematis sect. Fruticella. This study aids understanding of the distributional dynamics of Clematis sect.

Fruticella, and the results will help the conservation and sustainable use of these important woody plants in Chinese arid and semiarid areas.

\section{Introduction}

Ecological habitats and distributions of living organisms, community compositions, ecosystem structures, and global biodiversity have been significantly influenced by climate changes during the Quaternary period (Qiu, Fu \& Comes, 2011; Doxford \& Freckleton, 2012; Pio et al., 2014; Carvalho et al., 2015; Sun et al., 2015; Matías et al., 2017; Qin et al., 2017; Zhang et al., 2018; Wang et al., 2019; Mohammadi et al., 2019). During the last glaciation, global temperature was $5-12^{\circ} \mathrm{C}$ lower than they are now and the glacier areas were 8.4 times of 
46 the present time in China (Wang \& Liu, 2001; Li et al., 2004; Chen, Kang \& Liu, 2011). This 47 greatly affected plant distributions and many plant species significantly shrank their habitat during that time (Xu et al., 2017; Li et al., 2019). Furthermore, the ongoing changing climate of the past few decades has also been affecting living systems and the geographic distributions of organisms (Parmesan \& Yohe, 2003), and resolving the relationships between vegetation and climate dynamics has been a critical issue of ecology study (Bellard et al., 2012). The Fifth Assessment Report of the Intergovernmental Panel on Climate Change (IPCC) estimated that by the end of the 21 th century, average global temperatures will have increased by $0.3-4.5^{\circ} \mathrm{C}$ as greenhouse gas emissions continue to increase (IPCC, 2013). This will have major effects on future ecosystems and species distributions (Walck et al., 2011; Wang et al., 2019; Li et al., 2019). Distribution ranges of many plant species in the Northern Hemisphere may shift northward or to higher elevations in response to the future climate changes (Hof et al., 2011; Bai, Wei \& Li, 2018; Wang et al., 2019; Zhang, Zhang \& Tao, 2019).

Modeling the effects of climate change on the past and present habitats of different species across a landscape aids in understanding the organisms' potential responses to their changing environments going forward (Wang et al., 2019; Li et al., 2019; Zhang, Zhang \& Tao, 2019). Species distribution modeling (SDM) is widely used and has become a valuable tool for predicting species habitat suitability (Barbet-Massin et al., 2012; Miller, 2012; Zhang et al., 2012; Li \& Wang, 2013). With the availability of massive digitalized specimen records and highresolution environmental data, SDM is widely used to assess current potential geographical habitats and evaluate the effects of climate change in recent years (Konowalik, Proćków \& Proćków, 2017; Wang et al., 2018; Li et al., 2019). To accomplish such analyses, many algorithms have been developed in the past decades, such as DOMAIN (Carpenter, Gillison \& Winter, 1993), Maximum Entropy algorithm (Maxent) (Phillips, Anderson \& Schapire, 2006), Generalized Linear Model (GLM) (Hirzel, Helfer \& Metral, 2001), and the Generalized Additive Model (GAM) (Austin et al., 2009). Of all these models, Maxent has been a powerful tool and commonly used to assess the impacts of environmental factors on the suitable habitat of a given taxon (Hernandez et al., 2006; Bai, Wei \& Li, 2018; Li et al., 2019).

Drylands, including arid, semi-arid, and dry sub-humid ecosystems, constitute one of the earth's largest terrestrial biomes. They cover $41 \%$ of the earth's surface and support 38\% of the global human population (Maestre et al., 2012). In China, drylands cover approximately 50\% of 
77 the total land surface, and desertification has increased rapidly in recent years. A recent study

78 discovered that semi-arid regions that dominate the drylands in northern China have experienced 79 much warming and significant expansion over the last 60 years (Huang et al., 2019). Because

80 these regions (especially in the Loess Plateau of northern China) have suffered from overgrazing, 81 subsistence farming, deforestation, and severe water loss and soil erosion, the ecosystems in 82 these regions are highly vulnerable to effects rooted in the current global climate changes (Jiang 83 et al., 2013; Liu et al., 2013). Thus, the knowledge of the distributional shifts of dryland 84 vegetation responding to climate change in that area is urgently needed to aid conservation and 85 sustainability of its biodiversity.

Clematis sect. Fruticella s. str. (Ranunculaceae), consisting of several erect, shrubby species 87 that grow mainly on the Loess Plateau and in the northern Hengduan Mountains, is one of the 88 most important plant taxa in northern China's arid and semi-arid ecosystems (He, Liu \& Xie, 2018). Previous classifications broadly included all the shrubby Clematis species in this section (Prantl, 1888; Handel-Mazzetti, 1939; Tamura, 1967, 1995; Chang, 1980; Johnson, 1997; GreyWilson, 2000). However, the most recent taxonomic revisions (Wang, 2003; Wang \& Li, 2005a, 2005b) considered that this broadly define section may not be a natural group due to its diversified floral traits. So, they re-defined this section to include only five species with yellow, bell-shaped flowers. Because of their white, spreading flowers, other, previously included, shrubby species (C. lancifolia, C. delavayi, C. ispahanica, C. songarica, and C. phlebantha), were excluded (Wang, 2003; Wang \& Li, 2005b). Although the recent molecular phylogenetic studies did not include all of the Clematis sect. Fruticella member species, yellow-flowered $C$. fruticosa was found to be distantly related to white-flowered $C$. delavayi and $C$. ispahanica (Lehtonen, Christenhusz \& Falck, 2016), thus supporting the exclusion of the white-flowered species from the section.

According to the current taxonomic revision, Clematis sect. Fruticella s. str. (hereinafter inclusive) contains $C$. fruticosa, $C$. tomentella, C. canescens, $C$. nannophylla, and $C$. viridis (Wang, 2003; Wang \& Li, 2005a, 2005b). The former four species are found in the vast arid and semi-arid areas of the Loess Plateau of northern China, and some populations extend to the Gobi of Mongolia. The latter species, $C$. viridis, grows on the windy and arid slopes of north Hengduan Mountains (Figure 1) and the uppermost Yangtze River's valley. Unlike most of the other climbing species of Clematis, sect. Fruticella has strikingly different characteristics. 
108 Besides being erect shrubs, the species' well-branched woody stems often have simple and 109 reduced leaves, specialized adaptations that minimize water loss in their arid and semi-arid 110 habitats. Plants of Clematis sect. Fruticella are cold and drought resistant and heliophilous. The 111 pollination system of this section is obligate out-crossing but self-compatible. The major 112 pollinators are Amegill aparhypate and Apis cerana (Hou et al., 2016).

113 Plants in Clematis sect. Fruticella play important roles in the dryland ecosystems in northern 114 China and have great horticultural value. Clematis fruticosa and C. nannophylla are typical 115 vegetation components of Chinese Loess Plateau and are often used in raised bed and rock 116 garden landscapes (Grey-Wilson, 2000). Because of its drought resistance and easy propagation, 117 C. tomentella, along with Hedysarum scoparium, Caragana korshinskii, Calligonum 118 mongolicum, and other xerophytic species, was used in straw checkerboard barriers constructed 119 to stabilize sand in the National Nature Reserves in Ningxia Province (Guo et al., 2012; Ding et 120 al., 2013). With its excellent stress tolerance, Clematis fruticosa would also be a good candidate 121 for sand fixing and afforestation (Liu et al., 2016).

However, previous studies have focused mainly on the drought-resistance and horticultural 123 utility of this section (Guo et al., 2012; Ding et al., 2013; Liu et al., 2016). Few studies have examined the habitat and ecological factors that contribute to its past, current, and future distribution under climate changes. Expansion and contraction of its range during Quaternary glaciations may provide a forecast of future distributional fluctuations under climate change and show key habitat suitability factors that are crucial for maintaining its utility and for management planning. In this study, we propose hypotheses that during the Last Glacial Maximum (LGM) the distribution area of Clematis sect. Fruticella was the smaller than that of the current, and in the future the distribution centroid of this section will move northward or higher elevation in response to global warming.

The ecological niche modeling (ENM) analysis is typically performed for single species. Only a few studies performed ENM analysis at higher taxonomic levels, e.g. for the willow family (Salicaceae) as a whole (Li et al., 2019). The present study used ENM to simulate the potential distribution of Clematis sect. Fruticella for the following reasons: (1) The five species are closely related and share a similar climatic niche on a larger spatial scale. As emphasized by Li et al. (2019), one premise of ENM is that the ecological requirements and distributions of species are in equilibrium (Peterson et al., 2011). All the members of Clematis sect. Fruticella 
139 are important vegetation components in dryland of China. The habitat is unique in the genus

140 Clematis and even in Ranunculaceae (Wang \& Li, 2005a; He, Liu \& Xie, 2018); (2) The

141 accuracy of specimen identification is crucial for robust niche modeling and will greatly affect

142 the simulation results. The five species of Clematis sect. Fruticella are so closely related and

143 similar morphologically that the species identification within this section are problematic in all

144 the available online databases. For example, we can obtain 125 specimen records under the name

145 Clematis canescens in Chinese Virtual Herbarium (CVH, http://www.cvh.org.cn). However, more

146 than $90 \%$ of the specimens are misidentified according to the most current taxonomic revision

147 (Wang \& Li, 2005a). Most of the 125 specimens are actually $C$. tomentella, some of them are $C$.

148 viridis and C. fruticosa. The distribution data is likely biased by incorrectly identified species,

149 whereas the identification at the section level is far less prone to mis-identifications. In this case,

150 we can consider Clematis sect. Fruticella as a species aggregate. (3) We combined the

151 occurrence data of Clematis sect. Fruticella so the ENM results were able to fully convey this

152 section's geographical distribution patterns.

153 In the present study, we obtained a comprehensive occurrence dataset of Clematis sect.

154 Fruticella, as well as high-resolution environmental data of its distribution areas in China and

155 Mongolia. We used that data in Maxent to build species distribution models to project and

156 quantify Clematis sect. Fruticella habitat changes under a variety of past, present, and future

157 climate scenarios to determine what influences the distributional and ecological patterns of this

158 group of plants. Our results offer a reference to assist in conservation and sustainable utility of

159 shrubby Clematis resources for afforestation in the drylands of China.

160

161 Materials \& Methods

162 Spatial Data Compilation

163 Clematis sect. Fruticella is distributed mainly in northern China, with one species (C. viridis)

164 distributed in the north Hengduan Mountains and some populations of C. fruticosa and $C$.

165 canescens occurring in Mongolia. In those areas, the annual precipitation of $110-750 \mathrm{~mm}$ is lowest

166 in the north and increases going southward, as does the annual average temperature of -2 to $10{ }^{\circ} \mathrm{C}$.

167 Precipitation also decreases from the east to the west. Vegetation types are alpine shrub grassland

168 along river valleys for $C$. canescens, and desert shrub grassland and desert grassland for the other 169 species. 
From July 2015 to May 2019, we conducted several multisite surveys for Clematis sect.

171 Fruticella across its whole distribution area, including eastern Qinghai, northwest Sichuan, western

172 Gansu, Ningxia, Shanxi, Inner Mongolia, and Hebei provinces. Our distribution data were then

173 compiled from both our field data and the CVH online database. Two other online databases, the

174 Global Biodiversity Information Facility (http://www.gbif.org; GBIF Occurrence Download,

175 https://doi.org/10.15468/dl.nuge5a) and the National Specimen Information Infrastructure of China

176 (http://www.nsii.org.cn), were also consulted. We carefully checked the distribution records and

177 identified specimens according to the current taxonomic revision (Wang \& Li, 2005a). Distribution

178 records without geographic coordinates were assigned coordinates using Google Earth

179 (http://www.google.com/earth). Duplicates were removed from our analyses. Eight distribution

180 sites for $C$. canescens, 19 for $C$. viridis, 29 for $C$. tomentella, 43 for $C$. nannophylla, and 101 for $C$.

181 fruticosa were documented. In total, 200 records of Clematis sect. Fruticella were used in our

182 analysis (Table S1).

183 Environmental Variables

184 Current Environmental Scenario

185 Plants of Clematis sect. Fruticella are cold and drought resistant and heliophilous. The growth 186 and reproduction of this section may have been determined by various interacting factors, such as 187 temperature, precipitation, solar radiation, and soil (Zhen \& Liu, 2010; Liu et al., 2014; Yu et al., 188 2018; He, Liu \& Xie, 2018). Therefore, in this study, 35 environmental variables, including 189 climate, soil, UV-B radiation, and topography, were chosen for niche modeling analysis. We 190 obtained 19 bioclimatic variables with $2.5^{\prime}$ spatial resolution (also referred to as $5 \mathrm{~km}^{2}$ spatial 191 resolution) from WorldClim-Global Climate Data (http://www.worldclim.org/bioclim) (Hijmans et 192 al., 2005) and applied them to current, past, and future conditions. We also downloaded four 193 datasets (Wet days (wet), Ground frost frequency (frs), Water vapor (vap), and Cloud cover (cld)) 194 from the IPCC (http://www.ipcc-data.org/observ/clim/cru_ts2_1.html) (Mitchell \& Jones, 2005). 195 Six UV variables (Annual Mean UV-B (UVB1), UV-B Seasonality (UVB2), Mean UV-B of 196 Highest Month (UVB3), Mean UV-B of lowest Month (UVB4), Sum of Monthly Mean UV-B 197 during Highest Quarter (UVB5), and Sum of Monthly Mean UV-B during Lowest Quarter (UVB6) 198 were obtained from gIUV, a global UV-B radiation dataset for macroecological studies

199 (https://www.ufz.de/gluv/index.php?en=32435) (Beckmann et al., 2014). Growing degree days, 200 soil $\mathrm{pH}$, and soil organic carbon were acquired from the University of Wisconsin 
201 (http://nelson.wisc.edu/sage/data-and-models/atlas/maps.php) (New, Hulme \& Jones, 1999) and

202 three other variables: barren/very sparsely vegetated land (NVG), mapped water bodies, and global 203 elevation (GloElev) were downloaded from the Food and Agriculture Organization (ILASA \& 204 FAO, 2012). All these environmental variables were transferred into ASCII format using ArcGIS 20510.2 Conversion Tools and then overlapped with map of Asia that was obtained from the Database 206 of Global Administrative Areas (https://www.gadm.org/maps.html) and then used the result to 207 extract environmental data.

\section{Multicollinearity Analysis Among Variables}

Because many environmental variables are spatially correlated and strong correlation between the environmental variables may cause over-fitting and imprecise modeling (Hu \& Liu, 2014), we 21 first excluded environmental variables with 0 contribution values using the Maxent Jackknife test

212 (Aguirre-Gutiérrez et al., 2013). Then, we conducted a multicollinearity test in ArcGIS 10.2 to

213 evaluate relationships between the rest of the environmental variables and to eliminate

214 overcounting bias. Finally, we calculated Pearson correlation coefficients using the Band

215 Collection Statistics tool in ArcGIS 10.2 to check the correlations among the 35 bioclimatic 216 variables (Fourcade et al., 2014) and eliminate sampling bias. If a pair of variables were highly 217 correlated $(r \geq 0.8)$, only the most ecologically meaningful variables were kept (Aguirre-Gutiérrez 218 et al., 2013). As a result of these analyses, out of the original 35 environmental variables we 219 retained nine for subsequent evaluation.

\section{The Past and Future Climate Scenarios and Years}

221 Climate changes during the late Pleistocene, especially the last glacial-interglacial cycle, 222 greatly impacted vegetation and caused forest types to fluctuate in East Asia (Fang, 1991; Zhou, 223 Qiu \& Guo, 1991; Harrison et al., 2001). Because of this, we used three paleoclimate data sets: the 224 Last Interglacial period (LIG, about 120-140 ka), the Last Glacial Maximum (LGM, about $22 \mathrm{ka}$ ), 225 and the Mid Holocene (MH, about $6 \mathrm{ka}$ ) in the Community Climate System Model four (CCSM4) 226 global climate model (http://www.worldclim.org) to predict possible past distribution areas.

227 CCSM4 is one of the most efficient climate models that can simulate the influence of past and 228 future climatic changes on the distribution of plants (Abdelaal et al., 2019). This model has been 229 already successfully applied in similar studies (Arar et al., 2019; Li, Fan \& He, 2020).

We applied the Representative Concentration Pathways (RCPs) defined in the IPCC Fifth 
232 processes work than do the models in the previous four assessment reports (IPCC, 2013). RCPs, 233 including RCP 2.6, RCP4.5, RCP6.0, and RCP 8.5, are potential pathways of radiative forcing 234 values (measured as $+2.6,+4.5,+6.0$, and $+8.5 \mathrm{~W} / \mathrm{m}^{2}$, respectively) in the year 2100 relative to 235 pre-industrial values. We used four RCP combinations with the CCSM4 climate change modeling 236 data, where 2050 and 2070 use average emissions for the years 2041 to 2060 and 2061 to 2080, 237 respectively. For modeling analyses, we used the RCP 2.6-2050, RCP 2.6-2070, RCP 8.5-2050, 238 and RCP 8.5-2070 combinations with CCSM4 to simulate global climate responses to increased 239 greenhouse gas emissions.

Model Simulation

Based on distributional data and the selected environmental parameters, we used Maxent for SDM of past, current, and future climate conditions for the whole section, as well as for each species (Phillips et al., 2017). To estimate the capacity of the model, 25\% of the data was used for

244

245

246

247

248

249

250

251

252

253

254

255

256

257

258

259

260

261

262 testing, while $75 \%$ of the location point data was used for training. SDM was performed using the factors discussed in the previous paragraph, along with occurrence data. The algorithm either ran 1,000 iterations of the processes or continued until convergence was reached (threshold, 0.00001). Two methods were utilized to evaluate Maxent performance: the area under the receiver-operating characteristic curve (AUC) (Fielding \& Bell, 1997; Babar et al., 2012) and true skill statistic (TSS) (Allouche et al., 2006). AUC is a threshold-independent measurement for assessing model performance (Fielding \& Bell, 1997). The value of AUC varies from 0 to 1, with AUC more than 0.9 thought to be good prediction (Swets, 1988). Whereas, TSS varies from -1 and +1 and takes both omission and commission errors into account. TSS value from 0.70-0.85 indicates good performance, from 0.85-1.00 indicates excellent performance (Luo, Wang \& Lyu, 2017). The R package Biomod2 was applied to conduct TSS assessment (Thuiller et al., 2009, 2016).

We used the jackknife test to assess the significance of those variables, obtaining a range of values, which we reclassified into four categories of potential suitable habitat: high $(>0.6)$, moderate (0.4-0.6), low $(0.2-0.4)$, and none $(<0.2)$ in the final potential species distribution map (Zhang, Zhang \& Tao, 2019). Maxent generated a current, three past, and four future climate scenarios to calculate the SDM projections. The distribution shifts between two scenarios were explained by the movement of the central point (the centroid) of the suitable habitat. Suitable habitat changes from one period to the next were estimated by cross-checking the suitable habitat areas in the past and future scenarios against the present distribution area. 
264

265

266

267

268

269

270

271

272

273

274

275

276

277

278

279

280

281

282

283

284

285

286

287

288

289

290

291

292

293

\section{Results}

\section{Model Accuracy and Suitable Areas for Clematis sect. Fruticella}

Models for Clematis sect. Fruticella with a cross-validation AUC of 0.986 and a TSS value of 0.901 (excellent performance) indicated that the Maxent model can accurately predict the location of potential suitable habitat (Figure 2). The potential suitable habitat for the current scenario included Hebei, Inner Mongolia, Shanxi, Shaanxi, Ningxia, Gansu, Qinghai, Sichuan, Xizang, Xinjiang, Yunnan, and Liaoning provinces of China and Mongolia (Figure 2D). Among those, the most suitable areas are concentrated in the Loess Plateau and adjacent areas of northern China. The highly suitable areas cover $238,605 \mathrm{~km}^{2}$, the moderately suitable areas covers $486,505 \mathrm{~km}^{2}$, and the least suitable areas encompass $665,699 \mathrm{~km}^{2}$. The areas with low, medium, and high suitable habitats in the past and future scenarios are in Table S2.

\section{Key Environmental Factors Influencing the Current Habitat}

Jackknife results showed that among the proportions of variation of the nine model variables, GloElev (22.9\% of variation), UVB4 (22.2\%), Precipitation of Coldest Quarter (BIO19, 20.7\%), and Mean Temperature of Driest Quarter (BIO9, 18.5\%) contributed the greatest weights for the current scenario (Figure 3, Table 1). The cumulative contributions of these four environmental variables (84.3\%) were also the most important variables with the highest weights in the seven past and future scenarios (Table S3).

Based on the major variables' response curves, we obtained the thresholds (existence probability > 0.2): GloElev, ranging from 539 to $3620 \mathrm{~m}$; UV-B4, more than $300.5 \mathrm{~J} / \mathrm{m} 2 /$ day; all the tested amounts of BIO19, with a peak from $0-47.6 \mathrm{~mm}$ and; and $\mathrm{BIO}$, ranging from -20.7 to $12.3^{\circ} \mathrm{C}$ (Figure 4).

\section{Suitable Areas Under Climate Changes}

The SDM of the LIG (Figure 5B) estimates that southern and western Xinjiang, western and central Inner Mongolia, western Henan, northern Yunnan, southern Xizang, and Central Pakistan, had more suitable habitat $\left(153,522 \mathrm{~km}^{2}\right)$ than the current distributions. However, the suitable habitat in Xinjiang, Gansu, Ningxia, Inner Mongolia, western Sichuan, Shaanxi, Hebei and eastern Qinghai and Xizang provinces of China decreased significantly, and the habitat in Mongolia was completely lost. In total, there was $730,700 \mathrm{~km}^{2}$ less suitable habitat in the LIG than there is now. During the LGM, and compared to current amounts, estimated suitable habitat increased by 
$294173,431 \mathrm{~km}^{2}$, mainly in Gansu, Shaanxi, Shanxi, Henan, Inner Mongolia, Sichuan, and Xinjiang 295 provinces of China, but 174,027 $\mathrm{km}^{2}$ was lost, mainly in the northern, northeastern, and 296 southwestern areas of the current suitable habitat (Figure 5C, Table 2). The MH model was similar 297 to that of the LGM, with estimated habitat losses of $137,774 \mathrm{~km}^{2}$, mainly in the northern and 298 northeastern distribution areas, the Hengduan Mountains of China, and in Mongolia, but with 299 increases $\left(147,854 \mathrm{~km}^{2}\right)$ in the northern, southern, and western parts of the current habitat.

300

301

Of the future scenarios, RCP2.6 is based on low levels of greenhouse gas emissions. Maxent estimated that the suitable habitat would increase by $109,356 \mathrm{~km}^{2}$ by 2050 under that pathway, 302 mainly in eastern Qinghai-Xizang, western Sichuan, northern Gansu, and Inner Mongolia of China 303 and in Mongolia, but lost suitable habitat of $173,101 \mathrm{~km}^{2}$ would occur mainly in Central Xinjiang, western Inner Mongolia, southern Sichuan, and northern Yunnan provinces of China and in 305 Mongolia (Figure 5E, Table 2). By 2070, Maxent estimated that the range of suitable habitat would 306 increase by $124,350 \mathrm{~km}^{2}$ mainly in the northern edge of the current habitat, but $132,483 \mathrm{~km}^{2}$ of suitable habitat would be lost (Figure 5F, Table 2). Based on high levels of greenhouse gas 308 emissions (RCP 8.5), the estimated habitat in 2050 would increase mainly in the northern margin, but decrease in the western parts of the current suitable habitat (Figure 5G, Table 2). Under the same pathway, Maxent estimated that by 2070 the range of suitable habitat would increase in both the southern and northern margins of the current suitable habitat and decrease mainly in west 312 (Figure 5H).

\section{Shift of the Distribution Center of Suitable Habitat}

The current centroid of suitable habitat was estimated to be in Alxa League, Inner Mongolia (38 $\left.14^{\prime} 13^{\prime \prime} \mathrm{N}, 105^{\circ} 13^{\prime} 24^{\prime \prime} \mathrm{E}\right)$. However, during the LIG period, the habitat centroid was in northern Ningxia province $\left(40^{\circ} 42^{\prime} 46.8^{\prime \prime} \mathrm{N}, 101^{\circ} 54^{\prime} 32.4^{\prime \prime} \mathrm{E}\right)$. This centroid shifted to the southwest during the LGM $\left(37^{\circ} 48^{\prime} 47^{\prime \prime} \mathrm{N}, 105^{\circ} 3^{\prime} 22^{\prime \prime} \mathrm{E}\right)$. In the $\mathrm{MH}$, the centroid was very close to its current location $\left(37^{\circ} 58^{\prime} 38^{\prime \prime} \mathrm{N}, 104^{\circ} 49^{\prime} 35^{\prime \prime} \mathrm{E}\right)$. Looking to a possible future under RCP 2.6 , the centroid will have shifted eastward to central Ningxia Province ( $\left.38^{\circ} 12^{\prime} 11^{\prime \prime} \mathrm{N}, 106^{\circ} 22^{\prime} 53^{\prime \prime} \mathrm{E}\right)$ by 2050 , and then would move backward ( $\left.38^{\circ} 22^{\prime} 23^{\prime \prime} \mathrm{N}, 105^{\circ} 33^{\prime} 31^{\prime \prime} \mathrm{E}\right)$ by 2070 . Applying RCP 8.5 , the centroid is predicted to shift northeast (38 $\left.47^{\prime} 19^{\prime \prime} \mathrm{N}, 105^{\circ} 36^{\prime} 35^{\prime \prime} \mathrm{E}\right)$ by 2050 and then shift eastward to Ordos, Inner Mongolia $\left(38^{\circ} 40^{\prime} 4^{\prime \prime} \mathrm{N}, 106^{\circ} 47^{\prime} 42^{\prime \prime E}\right)$ by 2070. 


\section{Discussion}

326 The Loess Plateau of China, known by its arid and semi-arid climate, low vegetation

327

328

329

330

331

332

333

334

335

336

337

338

339

340

341

342

343

344

345

346

347

348

349

350

351

352

353

354

coverage, erodible soil, and extensive monsoonal influence, has some of the most severe soil and water loss conditions in the world (Fang et al., 2011; Jiang et al., 2013; Wu et al., 2019). This area's natural vegetation is a key factor controlling soil erosion and stopping desertification (Zheng, 2006; Fang et al., 2011). Species of Clematis sect. Fruticella members, important components of xerophytic vegetation in China (He, Liu \& Xie, 2018), are found over the entire Chinese Loess Plateau and in adjacent arid areas (Wang \& Li, 2005a). This study presented a detailed analysis of this native plant taxon's current suitable habitat, as well as its predicted habitat under past and future climate scenarios. Our goal was to provide important insights into the feasibility of using those species for soil fixation in the arid and semi-arid environments of northeast Asia.

Our models showed that Clematis sect. Fruticella could potentially be distributed in a wide range of arid or semi-arid areas in Mongolia and parts of Xinjiang, southeastern Xizang, and southern Sichuan provinces in northern and western China (Figure 2D) where it is currently not found. Moderately and highly suitable habitats predicted by our model are consistent with this section's actual present distribution $\left(725,110 \mathrm{~km}^{2}\right)$. Because the section's predicted distribution area was broader than its actual distribution area, this study provides more expanded areas for the cultivation of this section's species.

When the nine tested variables were run through the jackknife test (Figure 3), GloElev, UVB4, BIO19, and BIO9 were the dominant elements driving the section's potential and current distributions. The GloElev response curve (Figure 4) showed that the estimated suitable elevation for this section is 539 to $3,620 \mathrm{~m}$. This model estimation was highly consistent with, but a little wider, in range compared to the section's actual elevation. From specimen records, the most widely distributed species, Clematis fruticosa, occurs at 700 to 2,300 m. The western Loess Plateau species C. nannophylla has a wider elevation range, from 1,200 to 3,200 m. The most narrowly distributed species, $C$. canescens, also has a very narrow elevation range $(1,200$ to $1,500 \mathrm{~m}$ ). The widely distributed species C. tomentella often occurs at 1,300 to 2,200 m. Finally, the north Hengduan Mountains species C. viridis has the highest elevation range, from 2,700 to $3,600 \mathrm{~m}$. Therefore, the actual elevation distribution of the section is 700 to $3,600 \mathrm{~m}$. 
355

356

357

358

359

360

361

362

363

364

365

366

367

368

369

370

371

372

373

374

375

376

377

378

379

380

381

382

383

384

Non-ionizing solar UV-B radiation $(280-315 \mathrm{~nm})$ is an abiotic stress factor for sessile plant species (Nawkar et al., 2013; Blagojevic et al., 2019; Derebe et al., 2019). Too much UV-B exposure damages both cell membranes and DNA and can cause morphological changes (An et al., 2000; Schmitz \& Weissenbock, 2003; Kataria \& Guruprasad, 2012). However, as a major energy source, plants need low-level UV-B radiation to help regulate growth and development (Blunden \& Arndt, 2011). Since Clematis sect. Fruticella plants are heliophilous, it was no surprise that one of the UV-B factors, UV-B4, was one of the most important contributing factors in the model. It indicated that UV-B radiation must be at least $300.5 \mathrm{~J} / \mathrm{m}^{2} / \mathrm{day}$ for Clematis sect. Fruticella plants to thrive. Previous studies showed that long term UV-B exposure may result in smaller leaves and shorter internodes and plant heights (Antonelli et al., 1997; Krizek, Mirecki \& Britz, 2006). Compared to other majority number of climbing and often compound-leafed Clematis species, the erect shrubby plants of Clematis sect. Fruticella also have very reduced simple leaves. Perhaps those characters developed as an adaptive response to strong sunlight.

A temperature (BIO9) and a precipitation (BIO19) variable in our model each contributed greatly to the predicted distribution of Clematis sect. Fruticella. (Table 1). They indicated that precipitation during the winter and temperatures during the dry season were important determinants of the section's distribution. Currently, the section's area of distribution is influenced greatly by a monsoonal climate (Wang et al., 2019), in which the coldest and driest season of the year is winter. Plants of Clematis sect. Fruticella are dormant in winter and their physiological activities are weak. However, a certain amount of precipitation and temperature accumulation in this period are required for dormancy breaking, vegetative bud development, and flower bud differentiation (Xu et al., 2019).

Changing climate has affected species distributions and received much attention in recent ecological studies, including those that have shown that some plant species have shifted their distributions drastically during Quaternary climate changes (Lenoir et al., 2008; Qiu, Fu \& Comes, 2011). Distributions of many tree and shrub species typically showed latitudinal range shifts in response to glacial movements during the Quaternary (Petit et al., 2003; Ikeda \& Setoguchi, 2007; Qiu, Fu \& Comes, 2011). However, the estimated suitable habitat centroid of Clematis sect. Fruticella was very stable in our study. In our models, it shifted only slightly 
385 between the LIG era and the years 2050 and 2070, and no patterns of changing elevation were 386 found in those centroid shifts (Figure 6).

387 During the last glaciation, global temperature was $5-12{ }^{\circ} \mathrm{C}$ lower than they are now and the 388 glacier areas were 8.4 times of the present time in China (Wang \& Liu, 2001; Li et al., 2004;

389 Chen, Kang \& Liu, 2011). This greatly affected plant distributions. However, our model showed 390 that suitable habitat for Clematis sect. Fruticella in the LGM did not shrink as much, as might be 391 expected (Figure 5, Table 2). On the contrary, the smallest area of suitable habitat was estimated 392 to be in the LIG period (Figure 5, Table 2), when it was only about half of the current area, but 393 then expanded significantly in LGM. This situation is like those of other reported cold-adapted 394 plant taxa, such as species of Picea, Taxus, Tsuga, and Quercus (Li et al., 2013; Liu et al., 2013; 395 Sun et al., 2015; Yu et al., 2015; Du et al., 2017; Zhang et al., 2018), in which low and more 396 397 stable LGM temperatures created a dispersal opportunity for cold-adapted plant species (Stewart et al., 2009; Kozhoridze et al., 2015). Clematis is one of few cosmopolitan genera in the buttercup family, with some species found in subtropical to tropical areas. However, like most of the genera in Ranunculaceae, majority of Clematis species occur in temperate zones and are cold-adapted (e.g., sect. Montana, sect. Atragene, sect. Meclatis, and sect. Fruticella). Our models confirmed that the LGM's cold climate did not adversely affect Clematis sect. Fruticella distribution.

403 Study of the depositional sequences of paleosol and loess layers of the Loess Plateau showed 404 that there were five strong summer and four winter monsoon events in the LIG period, 405 demonstrating an unstable climate during that time (Guan et al., 2007). Paleoenvironmental 406 407 reconstruction of the Loess Plateau implied that both the highest temperature and precipitation amounts in the last 136,000 years occurred during the LIG period $\left(18.1^{\circ} \mathrm{C}\right.$, maximum mean annual temperature and 1,000 mm maximum mean annual precipitation) (Lu et al., 2007). That unstable and relatively warm, humid climate may have been the main reason that the suitable habitat for Clematis sect. Fruticella during the LIG period contracted to its smallest area.

In addition to the environmental factors discussed above, other factors, such as interspecific 413 period, the Loess Plateau had mainly forest and forest-steppe vegetation (Cai et al., 2013). Such 414 forest ecosystems would produce extensive shading, thus creating interspecific competition for 415 solar radiation, a distinct minus for Clematis sect. Fruticella. Another study showed that $C$. 
416 fruticosa, now common and widely distributed in Loess Plateau, requires outcrossing, even 417 though it is self-compatible (Hou et al., 2016). A forest environment could hinder pollen and 418 fruit migration and prevent long-distance species dispersal. These ecological factors could 419 contribute to the contraction of suitable habitat for Clematis sect. Fruticella during LIG.

420 Our model suggests that during the transition from the LIG to the LGM, the suitable habitat 421 of Clematis sect. Fruticella expanded to an area very similar to what is seen today. Thus, the 422 suitable habitat demonstrated stability from the LGM to the future scenarios. No significant area 423 expansion/contraction or latitudinal/altitudinal shifts were detected after the LGM. As the 424 climate changed from warm and humid (LIG) to cold and dry (LGM), the forest ecosystems were 425 then changed into steppe and desert steppe predominantly occupied by Artemisia and 426 Chenopodiaceae (Cheng \& Jiang, 2011). During that time, the cold and drought tolerances of 427 Clematis sect. Fruticella facilitated its adaption to the environment and fostered its expanded 428 distribution. To the $\mathrm{MH}$, the climate and vegetation of the Loess Plateau and adjacent areas were 429 like those of the present (Ge \& Wei, 2008; Cheng \& Jiang, 2011), so the predicted suitable 430 habitat of Clematis sect. Fruticella remains stable with only minor changes.

431 Distribution ranges of many plant species in the Northern Hemisphere may shift northward 432 or to higher elevations in response to the global warming in the future (Hof et al., 2011; Bai, Wei 433 \& Li, 2018; Wang et al., 2019; Zhang, Zhang \& Tao, 2019). However, Clematis sect. Fruticella 434 would likely experience very limited changes in suitable habitat in the future. Although plants of 435 this section are essentially cold adapted, they are also widely adaptable to warm temperatures 436 during summer. Studies have indicated that the semi-arid regions in China will continue to 437 expand, and less precipitation and soil moisture and increased drought frequency may occur 438 because of global warming (Chou et al., 2009; Huang et al., 2019). These changes will not 439 adversely affect the suitable habitat of the drought-resistant Clematis sect. Fruticella.

\section{Conclusions}

442 Investigating the effects of climate change on both plant distribution and plant response 443 mechanisms aids the development of effective conservation strategies and sustainable use of 444 biodiversity. According to our modeling, the predicted current potential range of Clematis sect. 445 Fruticella was broader than its current distribution range, and the GloElev, UVB4, BIO19, and 446 BIO9 variables most affected this section's distribution. Unlike many other plant taxa, Clematis 
447 sect. Fruticella underwent a significant range contraction during the LIG period, and then an

448

449

450

451

452

453

454

455

456

457

458

459

460

461

462

463

464

465

466

467

468

469

470

471

472

473

474

475

476

477

478 expansion during the LGM to amounts similar to present amounts. Cold, dry, and relatively stable climate, as well as steppe or desert steppe environments may have facilitated the range expansion of this cold-adapted and drought-resistant plant taxon during the LGM. Although climate warming will likely intensify in the future, the suitable habitat of Clematis sect.

Fruticella will not much change. Other factors, such as interspecific competition, human activities, and biological interactions (Liu et al., 2016) that could not be integrated into our modelling, may also affect the section's distribution. The results of our study help us understand distributional dynamics of Clematis sect. Fruticella and may aid the conservation and sustainable use of these important woody plants in Chinese arid and semiarid areas.

\section{Reference}

Abdelaal, M.; Fois, M.; Fenu, G.; Bacchetta, G. Using MaxEnt modeling to predict the potential distribution of the endemic plant Rosa arabica Crép. in Egypt. Ecol. Inform. 2019, 50, 68-75.

Aguirre-Gutiérrez, J.; Carvalheiro, L.G.; Polce, C.; van Loon, E.E.; Raes, N.; Reemer, M.; Biesmeijer J.C. Fitfor-purpose: species distribution model performance depends on evaluation criteria-Dutch Hoverflies as a case study. PLoS One 2013, 8, e63708.

Allouche, O.; Tsoar, A.; Kadmon, R. Assessing the accuracy of species distribution models: prevalence, kappa and the true skill statistic (TSS). J. Appl. Ecol. 2006, 43, 1223-1232

An, L.Z.; Feng, H.Y.; Tang, X.D.; Wang, X.L. Changes of microsomal membrane properties in spring wheat leaves (Triticum aestivum L.) exposed to enhanced ultraviolet-B radiation. J. Photochem. Photobiol. B, Biol. 2000, 57, 60-65.

Antonelli, F.; Grifoni, D.; Sabatini, F.; Zipoli, G. Morphological and physiological responses of bean plants to supplemental UV radiation in a Mediterranean climate. Pl. Ecol. 1997, 128, 127-136.

Arar, A.; Tabet, S.; Nouidjem, Y.; Bounar, R.; Chenchouni, H. Projected small-scale range reductions of Cedrus atlantica forests due to climate change at the Belezma National Park (Algeria). In: Exploring the Nexus of Geoecology, Geography, Geoarcheology and Geotourism: Advances and Applications for Sustainable Development in Environmental Sciences and Agroforestry Research. Springer: Cham, 2019; pp. 15-19.

Austin, M.P.; Smith, T.M.; Niel, K.P.V.; Wellington, A.B. Physiological responses and statistical models of the environmental niche: a comparative study of two co-occurring eucalyptus species. J. Ecol. 2009, 97, 469-507. 
479

480

481

482

483

484

485

486

487

488

489

490

491

492

493

494

495

496

497

498

499

500

501

502

503

504

505

506

507

508

509

510

511

512

513

514

Babar, S.; Amarnath, G.; Reddy, C.S.; Jentsch, A.; Sudhakar, S. Species distribution models: ecological explanation and prediction of an endemic and endangered plant species (Pterocarpus santalinus $\mathrm{L}$. f.). Curr. Sci. 2012, 102, 1157-1165.

Bai, Y.; Wei, X.; Li, X. Distributional dynamics of a vulnerable species in response to past and future climate change: a window for conservation prospects. PeerJ 2018, 6, e4287.

Barbet-Massin, M.; Jiguet, F.; Albert, C.H.; Thuiller, W. Selecting pseudo-absences for species distribution models: How, where and how many? Methods Ecol. Evol. 2012, 3, 327-338.

Beckmann, M.; Václavík, T.; Manceur, A.M.; Šprtová, L.; Wehrden, H.V.; Welk, E.; Cord, A.F. glUV: A global UV-B radiation dataset for macroecological studies. Methods Ecol. Evol. 2014, 5, 372-383.

Bellard, C.; Bertelsmeier, C.; Leadley, P.; Thuiller, W.; Courchamp, F. Impacts of climate change on the future of biodiversity. Ecol. Letters, 2012, 15, 365-377.

Blagojevic, D.; Lee, Y.; Xie, L.; Brede, D.A.; Nybakken, L.; Lind, O.C.; Tollefsen, K.E.; Salbu, B.; Solhaug, K.A.; Olsen, J.E . No evidence of a protective or cumulative negative effect of UV-B on growth inhibition induced by gamma radiation in Scots pine (Pinus sylvestris) seedlings. Photochem. Photobiol. Sci. 2019, 18, 1945-1962.

Blunden, J.; Arndt, D.S. State of the climate in 2011. Bull. Am. Meteorol. Soc. 2012, 93, S1-S282.

Cai, M.; Wei, M.; Xu, D.; Miao, Y.; Wu, F.; Pan, B. Vegetation and climate changes during three interglacial periods represented in the Luochuan loess-paleosol section, on the Chinese Loess Plateau. Quat. Int. 2013, 296, 131-140.

Carpenter, G.; Gillison, A.N.; Winter, J. DOMAIN: a flexible modelling procedure for mapping potential distributions of plants and animals. Biodivers. Conserv. 1993, 2, 667-680.

Carvalho, B.M.; Rangel, E.F.; Ready, P.D.; Vale, M.M. Ecological niche modelling predicts southward expansion of Lutzomyia (Nyssomyia) flaviscutellata (Diptera: Psychodidae: Phlebotominae), Vector of Leishmania (Leishmania) amazonensis in South America, under climate change. PLoS One 2015, 10, e0143282.

Chang, M.C. Clematis sect. Fruticella. In: Flora Reipublicae Popularis Sinicae, Sinicae Agendae Academiae Sinicae Edita, Ed.; Science Press: Beijing, China, 1980; Volume 28, pp. 147-156.

Chen, D.M.; Kang, H.Z.; Liu, C.J. An overview on the potential Quaternary glacial refugia of plants in China mainland. Bull. Bot. Res. 2011, 31, 623-632.

Cheng, Y.F.; Jiang, W.Y. Vegetation and climate changes since the Last Glacial Maximum in the northern Loess Plateau. Quat. Sci. 2011, 31, 982-989.

Chou, C.; Neelin, J.D.; Chen, C. A.; Tu, J.Y. Evaluating the "rich-get-richer" mechanism in tropical precipitation change under global warming. J. Clim. 2009, 22, 1982-2005.

Derebe, A.D.; Roro, A.G.; Asfaw, B.T.; Ayele, W.W.; Hvoslef-Eide, A.K. Effects of solar UV-B radiation exclusion on physiology, growth and yields of taro (Colocasia esculenta (L.)) at different altitudes in tropical environments of Southern Ethiopia. Sci. Horticul. 2019, 256, 108563.

Peer) reviewing PDF | (2019:11:43391:1:1:NEW 18 Jan 2020) 
515 Ding X.L.; Zhang X.; Guo Y.Q.; Liu W.S.; Liu B. Seedling raising and afforestation technology of Clematis 516 canescens. Ningxia J. Agri. Fores. Sci. Tech. 2013, 54, 25-33.

517 Doxford, S.W.; Freckleton, R.P. Changes in the large-scale distribution of plants: extinction, colonization and 518 the effects of climate. J. Ecol. 2012, 100, 519-529.

519 Du, F.K.; Hou, M.; Wang, W.; Mao, K.; Hampe, A. Phylogeography of Quercus aquifolioides provides novel

520

521

522

523

524

525

526

527

528

529

530

531

532

533

534

535

536

537

538

539

540

541

542

543

544

545

546

547

548

549 insights into the Neogene history of a major global hotspot of plant diversity in south-west China. $J$. Biogeogr. 2017, 44, 294-307.

Fang, H.; Li, Q.; Cai, Q.; Liao, Y. Spatial scale dependence of sediment dynamics in a gullied rolling loess region on the Loess Plateau in China. Environ. Earth Sci. 2011, 64, 693-705.

Fang, J.Q. Lake evolution during the last 30,000 years in China, and its implications for environmental change. Quat. Res. 1991, 36, 37-60.

Fielding, A.H.; Bell, J.F. A review of methods for the assessment of prediction errors in conservation presence/absence models. Environ. Conserv. 1997, 24, 38-49.

Fourcade, Y.; Engler, J.O.; Rödder, D.; Secondi, J. Mapping species distributions with Maxent using a geographically biased sample of presence data: a performance assessment of methods for correcting sampling bias. PloS One 2014, 9, e97122.

Ge Y.G.; Wei, M.J. Palaeo-vegetation and palaeo-environment change of last interglacial period in Xishan Mountain of Beijing. Geol. Sci. Techn. Inf. 2008, 27, 5-12.

Grey-Wilson, C. Clematis the genus. Timber Press: Portland, USA, 2000.

Guan, Q.; Pan, B.; Gao, H.; Li, B.; Wang, J.; Su, H. Instability characteristics of the East Asian Monsoon recorded by high-resolution loess sections from the last interglacial (MIS5). Sci. China Ser. D Earth Sci. 2007, 50, 1067-1075.

Guo, Y.Q.; Zhang, X.; Liu, W.S.; Liu, B. Forestation of Clematis canescens in Miao Erling in Tongxin County. J. Anhui Agri. Sci. 2012, 42, 16222-16223.

Handel-Mazzetti, H. Plantae Sinenses a Dre H. Smith annis 1921-1922, 1924 et 1934 lectae. XXXIII. Ranunculaceae. Acta Hort. Gotob. 1939, 13, 37-219.

Harrison, S.P.; Yu, G.; Takahara, H.; Prentice, I.C. Palaeovegetation: diversity of temperate plants in East Asia. Nature 2001, 413, 129-130.

He, J.; Liu, H.J.; Xie, L. Research advances of Clematis sect. Fruticella (Ranunculaceae). J. Nanjing Forest. Univ. (Nat. Sci. Ed.) 2018, 42, 156-162.

Hernandez, P.A.; Graham, C.H.; Master, L.L.; Albert, D.L. The effect of sample size and species characteristics on performance of different species distribution modeling methods. Ecography 2006, 29, $773-785$.

Hijmans, R.J.; Cameron, S.E.; Parra, J.L.; Jones, P.G.; Jarvis, A. Very high resolution interpolated climate surfaces for global land areas. Int. J. Climatol. 2005, 25, 1965-1978.

Peer] reviewing PDF | (2019:11:43391:1:1:NEW 18 Jan 2020) 
550

551

552

553

554

555

556

557

558

559

560

561

562

563

564

565

566

567

568

569

570

571

572

573

574

575

576

577

578

579

580

581

582

583

584

Hirzel, A.H.; Helfer, V.; Metral, F. Assessing habitat-suitability models with a virtual species. Ecol. Model. 2001, 145, 111-121.

Hof, C.; Levinsky, I.; Araújo, M.B.; Rahbek, C. Rethinking species' ability to cope with rapid climate change. Glob. Chang. Biol. 2011, 17, 2987-2990.

Hou, Q.Z.; Ren, Y.L.; Wen J.; Zhao, D.G.; Wang, S.Y. Breeding system characters and the adaptive significances of downward orientation flowers in Clematis fruticosa Turcz. Acta Bot. Boreal.-Occident. Sin. 2016, 36, 2283-2290

$\mathrm{Hu}, \mathrm{J} . ; \mathrm{Liu}, \mathrm{Y}$. Unveiling the conservation biogeography of a data-deficient endangered bird species under climate change. PLoS One 2014, 9, e84529.

Huang, J.; Ma, J.; Guan X.; Li, Y.; He, H. Progress in semi-arid climate change studies in China. Adv. Atmos. Sci. 2019, 36, 922-937.

IIASA; FAO. Global Agro-ecological Zones (GAEZ v3.0), IIASA, Laxenburg, Austria and FAO, Rome, Italy, 2012.

Ikeda, H.; Setoguchi, H. Phylogeography and refugia of the Japanese endemic alpine plant, Phyllodoce nipponica Makino (Ericaceae). J. Biogeogr. 2007, 34, 169-176.

IPCC. Climate Change 2013: The Physical Science Basis. Contribution of Working Group I to the Fifth Assessment Report of the Intergovernmental Panel on Climate Change, Stocker, T.F., Qin, D., Plattner, G.K., Tignor, M., Eds.; Cambridge University Press: Cambridge, United Kingdom and New York, NY, USA, 2013; pp. 1535, ISBN 978-1-107-05799-1.

Jiang, W.; Cheng, Y.; Yang, X.; Yang, S. Chinese Loess Plateau vegetation since the Last Glacial Maximum and its implications for vegetation restoration. J. Appl. Ecol. 2013, 50, 440-448.

Johnson M. Släktet Klematis. Magnus Johnson Plantskola AB: Södertälje, Sweden, 1997.

Kataria, S.; Guruprasad, K.N. Solar UV-B and UV-A/B exclusion e $\square$ ects on intraspecific variations in crop growth and yield of wheat varieties. Field Crops Res. 2012, 125, 8-13.

Konowalik, K.; Proćków, M.; Proćków, J. Climatic niche of Selinum alatum (Apiaceae, Selineae), a new invasive plant species in Central Europe and its alterations according to the climate change scenarios: Are the European mountains threatened by invasion? PLoS One 2017, 12, e0182793.

Kozhoridze, G.; Orlovsky, N.; Orlovsky, L.; Blumberg, D.G.; Golan-Goldhirsh, A. Geographic distribution and migration pathways of Pistacia-present, past and future. Ecography 2015, 38, 1141-1154.

Krizek, D.T.; Mirecki, R.M.; Britz, S.J. Inhibitory e $\square$ ects of ambient levels of solar UV-A and UV-B radiation on growth of cucumber. Physiol. Pl. 2006, 100, 886-893.

Lehtonen, S.; Christenhusz, M.J.; Falck, D. Sensitive phylogenetics of Clematis and its position in Ranunculaceae. Bot. J. Linn. Soc. 2016, 182, 825-867.

Lenoir, J.; Gégout, J.C.; Marquet, P.A.; de Ruffray, P.; Brisse, H. A significant upward shift in plant species optimum elevation during the 20th century. Science 2008, 320, 1768-1771.

Peer) reviewing PDF | (2019:11:43391:1:1:NEW 18 Jan 2020) 
585 Li, J.; Fan, G.; He, Y. Predicting the current and future distribution of three Coptis herbs in China under

586

587

588

589

590

591

592

593

594

595

596

597

598

599

600

601

602

603

604

605

606

607

608

609

610

611

612

613

614

615

616

617

618

619

620 climate change conditions, using the MaxEnt model and chemical analysis. Sci. Total Environ. 2020, 698, 134141.

Li J.J.; Shu, Q.; Zhou, S.Z.; Zhao, Z.J.; Zhang, J.M. Review and prospects of Quaternary glaciation research in China. J. Glaciol. Geocryol. 2004, 26, 235-243.

Li, L.; Abbott, R.J.; Liu, B.; Sun, Y.; Li, L.; Zou, J.; Liu, J. Pliocene intraspecific divergence and Plio-Pleistocene range expansions within Picea likiangensis (Lijiang spruce), a dominant forest tree of the Qinghai-Tibet Plateau. Mol. Ecol. 2013, 22, 5237-5255.

Li, W.; Shi, M.; Huang, Y.; Chen, K.; Sun, H.; Chen, J. Climatic change can influence species diversity patterns and potential habitats of Salicaceae plants in China. Forests 2019, 10, 220.

Li, X.; Wang, Y. Applying various algorithms for species distribution modelling. Integr. Zool. 2013, 8, 124135.

Liu M.; Zheng R.; Bai S.L.; Qing Y.; Yan W.; Jia X.W. Seasonal dynamics of arbuscular mycorrhizal fungal community in the rhizosphere of Clematis fruticosa in the Daqingshan Mountains, Inner Mongolia. Acta Bot. Boreal.-Occident. Sin. 2016, 36, 1891-1899.

Liu, J.; Möller, M.; Provan, J.; Gao, L.M.; Poudel, R.C.; Li, D.Z. Geological and ecological factors drive cryptic speciation of yews in a biodiversity hotspot. New Phytol. 2013, 199, 1093-1108.

Liu, Y.N.; Wang, L.H.; Zhang, L.J.; Han, R.S.; Zhang, G.S. Physiological response of Clematis fruticosa under water stress. Nor. Horticul. 2014, 17, 71-74.

Liu, Y.Y.; van Dijk, A.I.J.M.; McCabe, M.F.; Evans, J.P.; de Jeu, R.A.M. Global vegetation biomass change (1988-2008) and attribution to environmental and human drivers, Glob. Ecol. Biogeogr. 2013, 22, 692705.

Lu, H.Y.; Wu, N.Q.; Liu, K.B.; Jiang, H.; Liu, T.S. Phytoliths as quantitative indicators for the reconstruction of past environmental conditions in China II: palaeoenvironmental reconstruction in the Loess Plateau. Quat. Sci. Rev. 2007, 26, 759-772.

Luo, M.; Wang, H.; Lyu, Z. Evaluating the performance of species distribution models Biomod2 and MaxEnt using the giant panda distribution data. J. Appl. Ecol., 2017, 28, 4001-4006.

Maestre, F.T.; Quero, J.L.; Gotelli, N.J.; Escudero, A.; Ochoa, V.; Delgado-Baquerizo, M.; García-Palacios, P. Plant species richness and ecosystem multifunctionality in global drylands. Science 2012, 335, 214-218.

Matías, L.; Linares, J.C.; Sánchez-Miranda, Á.; Jump, A.S. Contrasting growth forecasts across the geographical range of Scots pine due to altitudinal and latitudinal differences in climatic sensitivity. Glob. Chang. Biol. 2017, 23, 4106-4116.

Miller, J. A. Species distribution models: Spatial autocorrelation and non-stationarity. Prog. Phys. Geogr. 2012, 36, 681-692.

Mitchell, T.D.; Jones, P.D. An improved method of constructing a database of monthly climate observations and associated high-resolution grids. Int. J. Climatol. 2005, 25, 693-712.

Peer) reviewing PDF | (2019:11:43391:1:1:NEW 18 Jan 2020) 
621 Mohammadi, S.; Ebrahimi, E.; Moghadam, M.S.; Bosso, L. Modelling current and future potential 622 distributions of two desert jerboas under climate change in Iran. Ecol. Inform. 2019, 52, 7-13.

623 Nawkar, G.M.; Maibam, P.; Park, J.H.; Sahi, V.P.; Lee, S.Y.; Kang, C.H. UV-induced cell death in plants. Int. 624 J. Mol. Sci. 2013, 14, 1608-1628.

625 New, M.; Hulme, M.; Jones, P. Representing twentieth-century space-time climate variability. Part I:

626 Development of a 1961-1990 mean monthly terrestrial climatology. J. Clim. 1999, 12, 829-856.

627 Parmesan, C.; Yohe, G. A globally coherent fingerprint of climate change impacts across natural $628 \quad$ systems. Nature 2003, 421, 37.

629 Peterson, A.T.; Soberón, J.; Pearson, R.G.; Anderson, R.P.; Martínez-Meyer, E.; Nakamura, M.; Araújo, M.B. 630 Ecological niches and geographic distribution. Monogr. Popul. Biol. 2011, 49, 328.

631 Petit, R.J.; Aguinagalde, I.; de Beaulieu, J.L.; Bittkau, C.; Brewer, S.; Cheddadi, R.; Ennos, R.; Fineschi, 632 S.; Grivet, D.; Lascoux, M.; Mohanty, A.; Müller-Starck, G.; Demesure-Musch, B.; Palmé, A.; Martín, 633 J.P.; Rendell, S.; Vendramin, G.G. Glacial refuges: hotspots but not melting pots of genetic diversity. $634 \quad$ Science 2003, 300, 1563-1565.

635 Phillips, S.J.; Anderson, R.P.; Dudík, M.; Schapire, R.E.; Blair, M.E. Opening the black box: An open-source release of Maxent. Ecography 2017, 40, 887-893.

637 Phillips, S.J.; Anderson, R.P.; Schapire, R.E. Maximum entropy modeling of species geographic

638 distributions. Ecol. Model. 2006, 190, 231-259.

639 Pio, D.V.; Engler, R.; Linder, H.P.; Monadjem, A.; Cotterill, F.P.D; Taylor, P.J.; Schoeman, M.C.; Price,

640 B.W.; Villet, M.H.; Eick, G.; Salamin, N.; Guisan, A. Climate change effects on animal and plant

641 phylogenetic diversity in southern Africa. Glob. Chang. Biol. 2014, 20, 1538-1549.

642 Prantl, K. Clematis. Beträge zur Morphologie und Systematik der Ranunculaceen. Bot. Jahrb. 1888, 9, 325$643 \quad 373$.

644 Qin, H.; Dong, G.; Zhang, Y.; Zhang, F.; Wang, M. Patterns of species and phylogenetic diversity of Pinus tabuliformis forests in the eastern Loess Plateau. For. Ecol. Manage 2017, 394, 42-51.

646 Qiu, Y.X.; Fu, C.X.; Comes, H.P. Plant molecular phylogeography in China and adjacent regions: Tracing the genetic imprints of Quaternary climate and environmental change in the world's most diverse temperate flora. Mol. Phylogenet. Evol. 2011, 59, 225-244.

Schmitz, R.; Weissenbock, G. Contribution of phenolic compounds to the UV-B screening capacity of developing barley primary leaves in relation to DNA damage and repair under elevated UV-B levels. Photochem. 2003, 64, 243-255.

Stewart, J.R.; Lister, A.M.; Barnes, I.; Dalén, L. Refugia revisited: individualistic responses of species in space and time. Proc. Biol. Sci. 2009, 277, 661-671.

Sun, Y.; Li, L.; Li, L.; Zou, J.; Liu, J. Distributional dynamics and interspecific gene flow in Picea likiangensis 656 and P. wilsonii triggered by climate change on the Qinghai-Tibet Plateau. J. Biogeogr. 2015, 42, 475484. 
657 Swets, J.A. Measuring the accuracy of diagnostic systems. Sciences 1988, 240,1285-1293.

658 Tamura, M. Archiclematis \& Clematis. In Die Natürlichen Pflanzenfamilien, 2rd ed.; Hiepko, P., Ed.; Duncker 659 \& Humblot: Berlin, Germany, 1995; Volume 17, pp. 366-387.

660

Tamura, M. Morphology, ecology and phylogeny of the Ranunculaceae. VII. Sci. Rep. Osaka Univ. 1967, 16,

661 $21-43$.

662 Thuiller, W.; Lafourcade, B.; Engler, R.; Araújo, M.B. Biomod: A platform for ensemble forecasting of 663 species distributions. Ecography, 2009, 32, 369-373.

664 Thuiller, W.; Georges, D.; Engler, R.; Breiner, F.; Georges, M.D.; Thuiller, C.W. Package 'biomod2'. Species

665

666

667

668

669

670

671

672

673

674

675

676

677

678

679

680

681

682

683

684

685

686

687

688

689 distribution modeling within an ensemble forecasting framework. 2016, https://CRAN. R-project. org $/$ package $=$ biomod 2 .

Walck, J.L.; Hidayati, S.N.; Dixon, K.W.; Thompson, K.E.N.; Poschlod, P. Climate change and plant regeneration from seed. Glob. Chang. Biol. 2011, 17, 2145-2161.

Wang, D.; Cui, B.; Duan, S.; Chen, J.; Fan, H.; Lu, B.; Zheng, J. Moving north in China: The habitat of Pedicularis kansuensis in the context of climate change. Sci. Total Environ. 2019, 97, 133979.

Wang, H.; Lu, H.; Zhang, H.; Yi, S.; Gu, Y.; Liang, C. Grass habitat analysis and phytolith-based quantitative reconstruction of Asian monsoon climate change in the sand-loess transitional zone, northern China. Quat. Res. 2019, 92, 519-529.

Wang, R.; Li, Q.; He, S.; Liu, Y.; Wang, M.; Jiang, G. Modeling and mapping the current and future distribution of Pseudomonas syringae pv. actinidiae under climate change in China. PloS One 2018, 13, $\mathrm{e} 0192153$.

Wang, W.T. A revision of Clematis sect. Clematis (Ranunculaceae). Acta Phytotax. Sin. 2003, 41, 1-62.

Wang, W.T.; Li, L.Q. A revision of Clematis sect. Fruticella (Ranunculaceae). Acta. Phytotax. Sin. 2005a, 43, 193-209.

Wang, W.T.; Li, L.Q. A new system of classification of the genus Clematis (Ranunculaceae). Acta. Phytotax. Sin. 2005b, 43, 431-488.

Wang, Z.T.; Liu, C.H. Geographical characteristics of the distribution of glaciers in China. J. Glaciol. Geocryol. 2001, 23, 231-237.

Wu, J.; Miao, C.; Duan, Q.; Lei, X.; Li, X.; Li, H. Dynamics and attributions of baseflow in the semiarid Loess Plateau. J. Geophys. Res. Atmos. 2019, 124, 3684-3701.

Xu, D.; Zhuo, Z.; Wang, R.; Ye, M.; Pu, B. Modeling the distribution of Zanthoxylum armatum in China with MaxEnt modeling. Glob. Ecol. Conserv. 2019, 19, e00691.

Xu, Z. P.; Zhang, J.Q.; Wan, T.; Cai, P.; Yi, W.D. Study on the history distribution pattern of Gymnocarpos przewalskii and refuge area. Acta Bot. Bor.-Occid. Sin. 2017, 37, 2074-2081. 
690 Yu, H.; Zhang, Y.; Liu, L.; Qi, W.; Li, S.; Hu, Z. Combining the least cost path method with population

691 genetic data and species distribution models to identify landscape connectivity during the late

692 Quaternary in Himalayan hemlock. Ecol. Evol. 2015, 5, 5781-5791.

693 Yu, H.R.; Li, Q.F.; Jia, Y.S.; He, Y.M. Study on dormancy and germination characteristics of four kinds of

694 shrub plant seeds. Nor. Horticul. 2018, 22, 88-93.

695 Zhang, A.P.; Wang, Y.; Xiong, Q.L.; Wu, X.G.; Sun, X.M.; Huang, Y.M.; Zhang, L.; Pan, K.W. Distribution

696 changes and refugia of three spruce taxa since the last interglacial. J. Appl. Ecol. 2018, 29, 2411-2421.

697 Zhang, K.; Yao, L.; Meng, J.; Tao, J. Maxent modeling for predicting the potential geographical distribution of 698 two peony species under climate change. Sci. Total Environ. 2018, 634, 1326-1334.

699 Zhang, K.; Zhang, Y.; Tao, J. Predicting the potential distribution of Paeonia veitchii (Paeoniaceae) in China 700 by incorporating climate change into a Maxent model. Forests 2019, 10, 190.

701 Zhang, M.G.; Zhou, Z.K.; Chen, W.Y.; Slik, J.F.; Cannon, C.H.; Raes, N. Using species distribution modeling 702 to improve conservation and land use planning of Yunnan, China. Biol. Conserv. 2012, 153, 257-264.

703 Zhen, H.Y.; Liu, Y. Study on seeds biological characteristics of 2 ornamental plant of sect. Fruticella. Seed $7042010,29,42-44$.

705 Zheng, F.L. Effect of vegetation changes on soil erosion on the Loess Plateau. Pedosphere 2006, 16, 420-427.

706 Zhou, Y.; Qiu, G.; Guo, D. Changes of permafrost in China during the Quaternary. In Quaternary Geology and 707 Environment in China, Liu, T., Ed.; Science Press: Beijing, China, 1991; pp. 86-94. 
Figure 1

Distribution of Clematis sect. Fruticella in China and Mongolia.

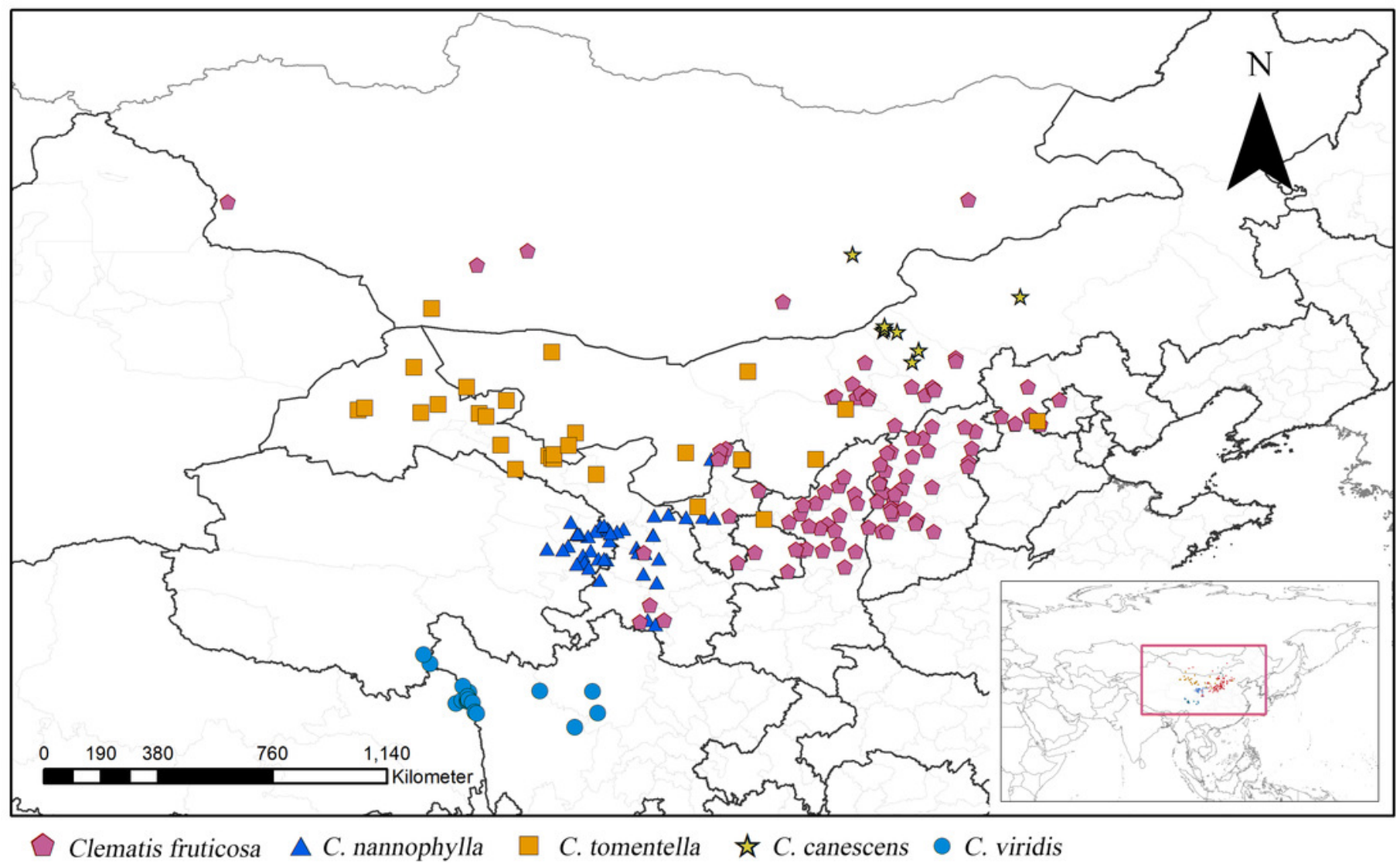


Figure 2

Potential suitable distribution areas for Clematis sect. Fruticella predicted using Maxent modeling of eight scenarios.

(A) Last interglacial (B) Last glacial Maximum. (C) Mid Holocene. (D) Current. (E) Year of 2050 (under RCP2.6). (F) Year of 2070 (under RCP2.6). (G) Year of 2050 (under RCP8.5). (H) Year of 2070(under RCP8.5). RCP: representative concentration pathway. 


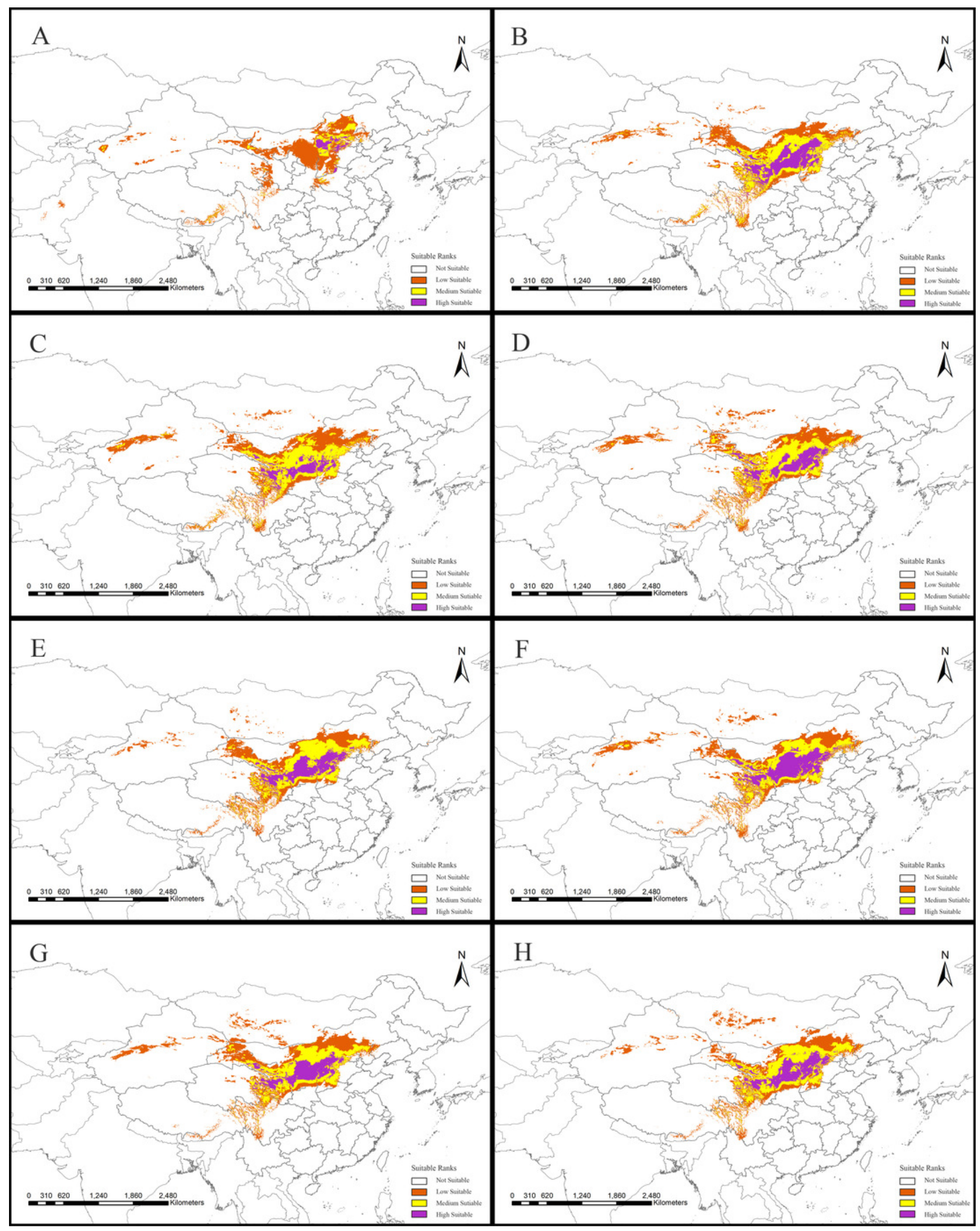


Figure 3

Jackknife test results showing the relative importance (training gain) of the nine selected environmental variables for Clematis sect. Fruticella.

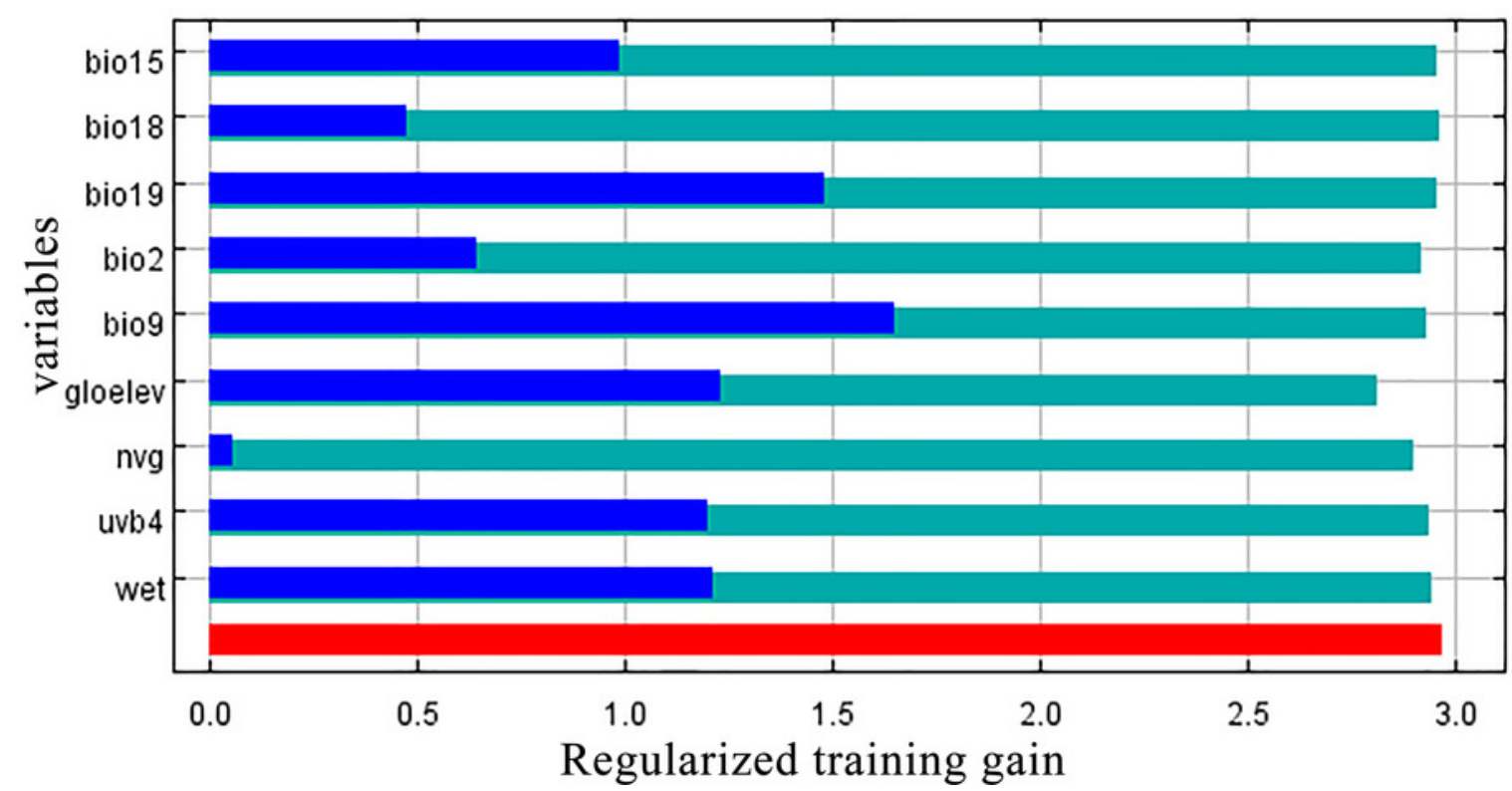

Without variable

With only variable

With all variables 
Figure 4

Response curves for the four most important environmental predictors in the Clematis sect. Fruticella distribution model.

(A) Elevation. (B) Mean UV-B of Lowest Month. (C) Precipition of Coldest Quarter. (D) Mean

Temperature of Driest Quarst.
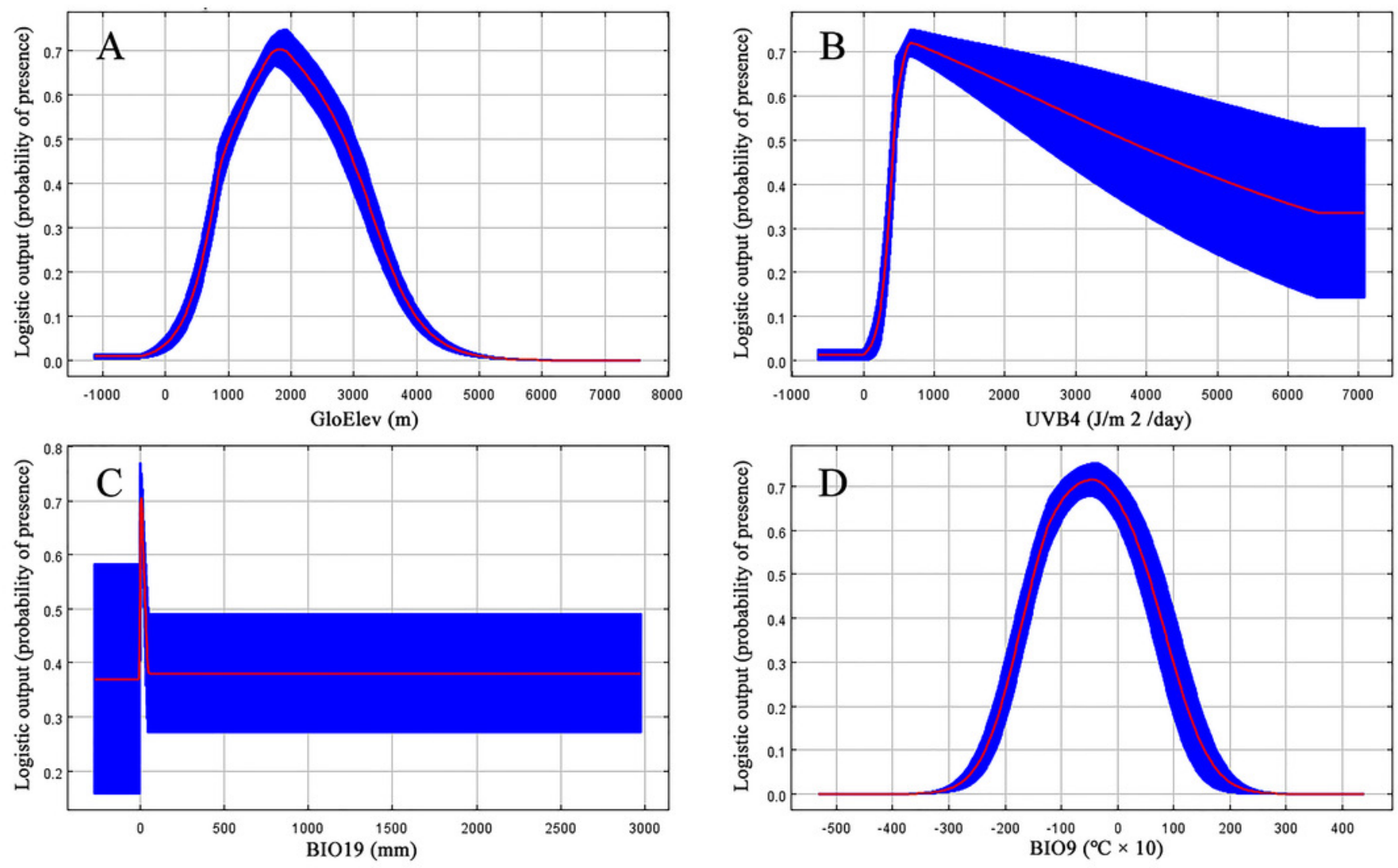


\section{Figure 5}

Species distribution models (SDMs) of Clematis sect. Fruticella.

Models B through $\mathrm{H}$ reflect habitat differences compared to the current model A. (A) Current.

(B) Last Interglacial. (C) Last Glacial Maximum. (D) Mid Holocene. (E) Year of 2050 (under

RCP2.6). (F) Year of 2070 (under RCP2.6). (G) Year of 2050 (under RCP8.5). (H) Year of 2070(under RCP8.5). RCP: representative concentration pathway. 


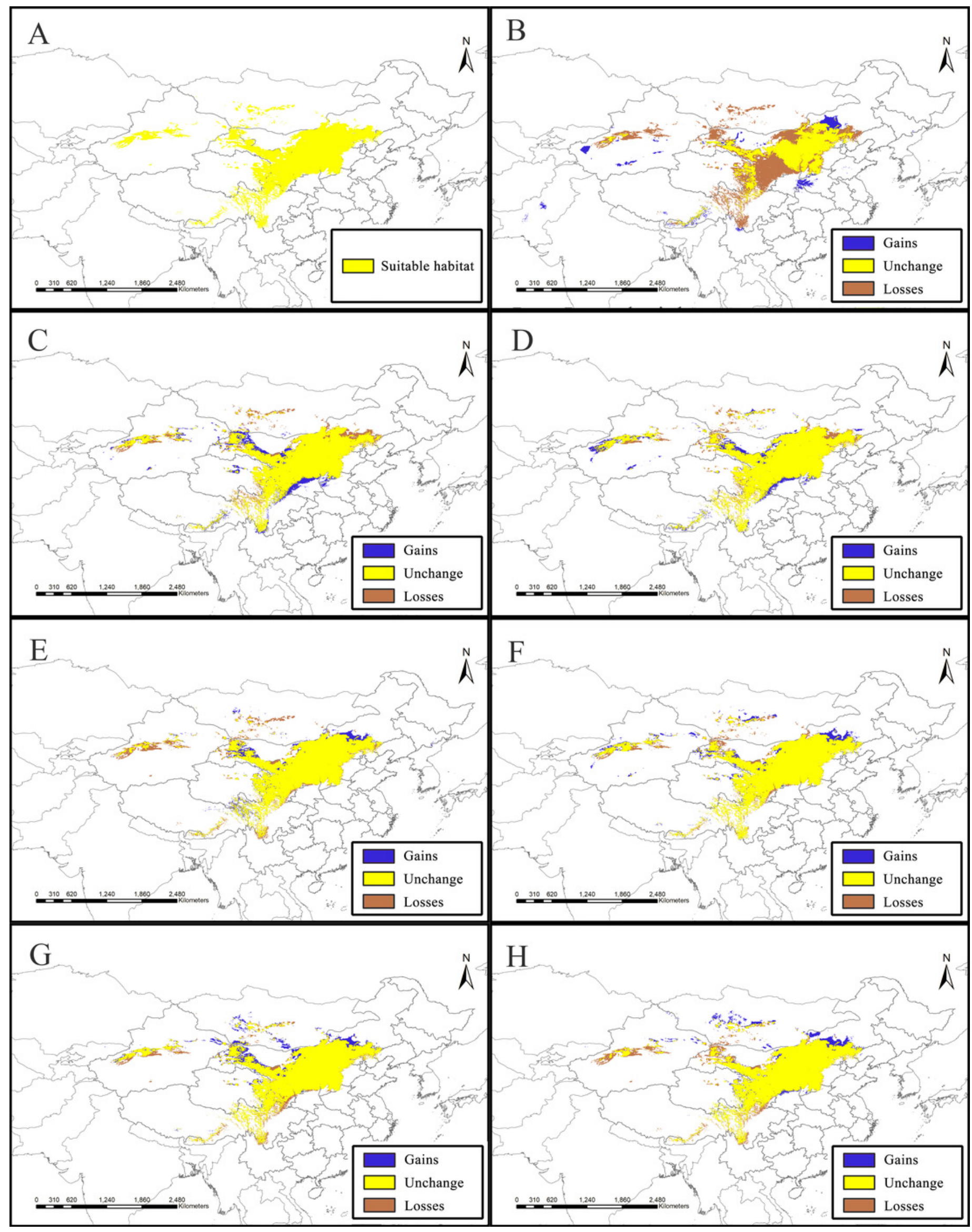


Figure 6

Core distributional shifts of Clematis sect. Fruticella under the four future and three past climate scenarios.

The distribution centroids are all in northern China. RCP: representative concentration pathway. 


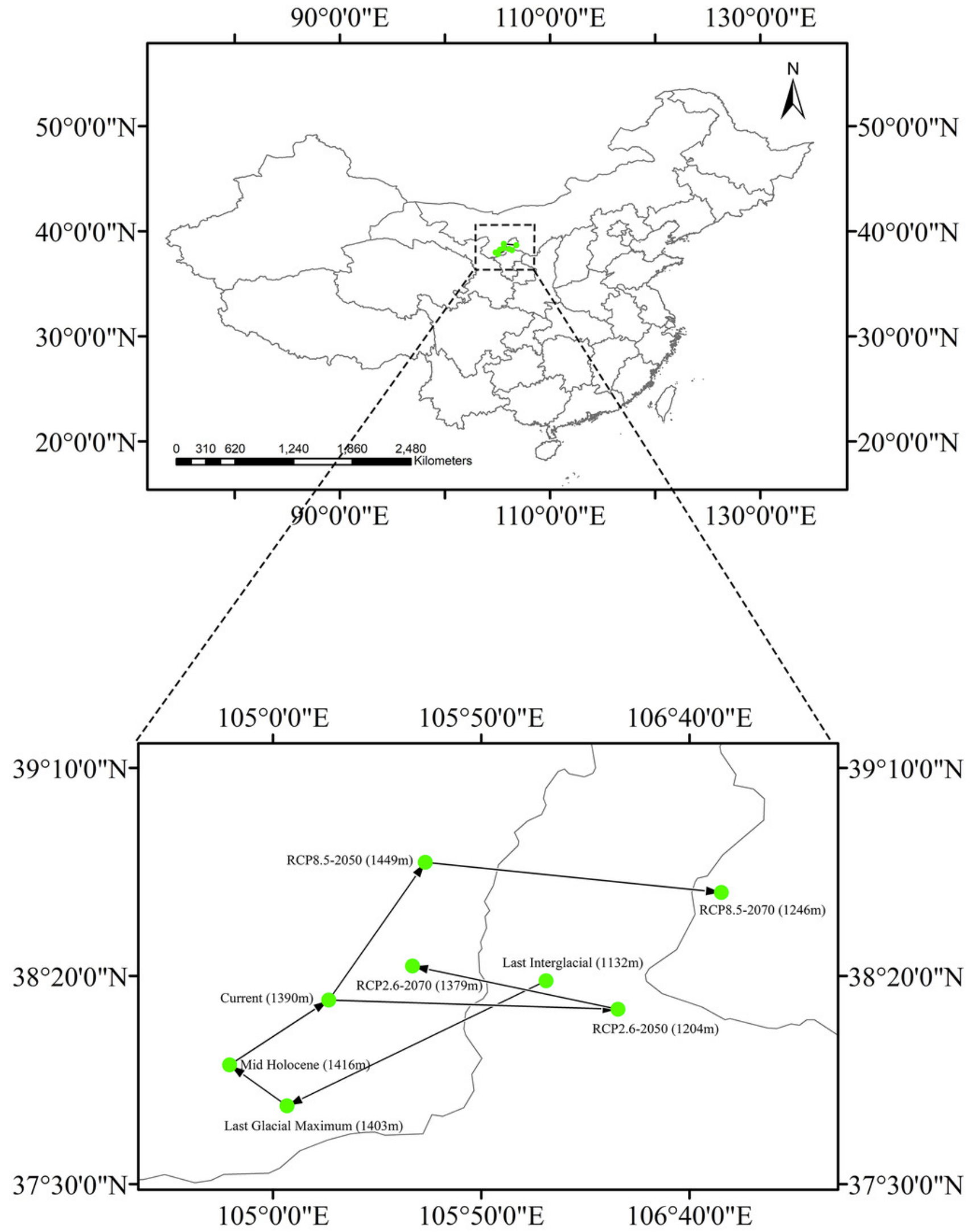




\section{Table $\mathbf{1}$ (on next page)}

Percentage contributions and permutation importance of the variables included in the Maxent models for Clematis sect. Fruticella. 


\section{Table 1:}

2 Percentage contributions and permutation importance of the variables included in the Maxent models for Clematis sect.

3 Fruticella.

\begin{tabular}{|c|c|c|c|}
\hline Environmental Variables & Resolution & Unit & Contribution (\%) \\
\hline Elevation (GloElev) & $30^{\prime \prime} \times 30^{\prime \prime}$ & $\mathrm{m}$ & 22.9 \\
\hline Mean UV-B of Lowest Month (UVB4) & $15^{\prime} \times 15^{\prime}$ & $\mathrm{J} / \mathrm{m}^{2} /$ day & 22.2 \\
\hline Precipitation of Coldest Quarter (BIO19) & $2.5^{\prime} \times 2.5^{\prime}$ & $\mathrm{mm}$ & 20.7 \\
\hline Mean Temperature of Driest Quarter (BIO9) & $2.5^{\prime} \times 2.5^{\prime}$ & ${ }^{\circ} \mathrm{C} \times 10$ & 18.5 \\
\hline barren/very sparsely vegetated land (NVG) & $5^{\prime} \times 5^{\prime}$ & & 7.5 \\
\hline Mean Diurnal Range (Mean of monthly ( $\max -\min )$ temp) (BIO2) & $2.5^{\prime} \times 2.5^{\prime}$ & ${ }^{\circ} \mathrm{C} \times 10$ & 2.8 \\
\hline Wet days (WET) & $30^{\prime} \times 30^{\prime}$ & d. & 2.2 \\
\hline Precipitation of Warmest Quarter (BIO18) & $2.5^{\prime} \times 2.5^{\prime}$ & $\mathrm{mm}$ & 2 \\
\hline Precipitation Seasonality (Coefficient of Variation) (BIO15) & $2.5^{\prime} \times 2.5^{\prime}$ & $\mathrm{mm}$ & 1.1 \\
\hline
\end{tabular}

4 


\section{Table 2 (on next page)}

Dynamic changes in the distribution area for Clematis sect. Fruticella under four future and three past climate scenarios compared to the current suitable habitat area. 
1 Table 2:

2 Dynamic changes in the distribution area for Clematis sect. Fruticella under four

3 future and three past climate scenarios compared to the current suitable habitat area.

\begin{tabular}{cccc} 
Scenarios & Increased $\left(\mathrm{km}^{2}\right)$ & Unchanged $\left(\mathrm{km}^{2}\right)$ & Decreased $\left(\mathrm{km}^{2}\right)$ \\
\hline Last interglacial & $153,522.601$ & $660,109.5024$ & $730,700.3814$ \\
Last Glacial Maximum & $173,431.2386$ & $121,6782.014$ & $174,027.8697$ \\
Mid Holocene & $147,854.6056$ & $125,3035.203$ & $137,774.6803$ \\
${ }^{1}$ RCP2.6-2050 & $109,356.1992$ & $121,7708.362$ & $173,101.5214$ \\
RCP2.6-2070 & $124,350.4807$ & $125,8326.379$ & $132,483.5045$ \\
RCP8.5-2050 & $146,755.5483$ & $124,6927.585$ & $143,882.2986$ \\
RCP8.5-2070 & $123,800.952$ & $1,200,798.581$ & $190,011.3027$ \\
\hline
\end{tabular}

$4 \quad{ }^{1} \mathrm{RCP}$ : representative concentration pathway

5 